\title{
LA PROTECCIÓN PENAL DEL TRABAJO
}

\author{
JAVIER ARÉVALO VELA*
}

\begin{abstract}
Resumen
Se analiza conceptos generales sobre Derecho penal del trabajo, así como propone algunas medidas de política criminal respecto de los delitos laborales.
\end{abstract}

Palabras clave: Derecho penal del trabajo - Delitos laborales.

\begin{abstract}
Analyzes general concepts of Criminal Labor Law and proposes a few measures of criminal policy for labor offenses.

Key words: Criminal Labor Law - Labor Offenses.

\section{Sumario}

1.- Introducción. 2.- El Derecho penal como medio de control social. 3.Derecho penal y Derecho penal del trabajo 4.- Derecho penal del trabajo y bien jurídico. 5.- Derecho penal del trabajo última ratio. 6.- Formación histórica del Derecho penal del trabajo. 7.- Derecho penal del trabajo y política criminal. 8.- Los delitos laborales en el Código Penal de 1991 y leyes especiales. 9.- Conclusiones.
\end{abstract}

\section{INTRODUCCIÓN}

En nuestro medio resulta una noticia diaria la comisión de hechos que lesionan los derechos de los trabajadores, muchos de los cuales no son objeto de sanción alguna, sea porque no están tipificados como delitos o porque la autoridad competente no se preocupa de investigarlos y reprimirlos. En las líneas siguientes presentaremos unas breves reflexiones sobre una disciplina jurídica poco difundida, pero que tiene mucho que ver con este tema: el Derecho penal del trabajo.

\section{EL DERECHO PENAL COMO MEDIO DE CONTROL SOCIAL}

Toda sociedad moderna, basada en un ordenamiento democrático, tiene por finalidad garantizar el bienestar común de sus integrantes, a efectos que

\footnotetext{
* Juez Supremo Titular de la Corte Suprema de Justicia de la República - Poder Judicial del Perú. Presidente de la Segunda Sala de Derecho Constitucional y Social Transitoria de la Corte Suprema. Profesor de la Maestría en Derecho del Trabajo en la Universidad San Martín de Porres y de la Academia de la Magistratura.
} 
libremente dentro de ella se puedan realizar como personas; es en la búsqueda de esa finalidad trascendente que la propia sociedad se ve obligada a imponer diversas regulaciones a la conducta de los individuos que la integran con el objeto de evitar que incurran en comportamientos que afecten el logro del desarrollo colectivo, poniendo incluso en peligro la subsistencia de la sociedad como tal. Estas limitaciones al comportamiento de los individuos constituyen el control social.

En opinión de VILLAVICENCIO: “...el control social busca garantizar que las personas se sometan a las normas de convivencia, dirigiendo satisfactoriamente los procesos de socialización" ${ }^{\prime 1}$.

El control social puede adoptar dos modalidades: los controles informales y los controles formales.

Los controles informales se caracterizan porque el Estado no interviene de manera represiva sobre los individuos, sino que es la presión social la que persigue el cambio de actitud del sujeto infractor de reglas sociales y ocasionalmente lo sanciona con el reproche del grupo.

En esta forma de control social influye la escuela, la familia, el medio social y profesional, etc. que rechazan a la persona que incurre en un comportamiento disfuncional.

En el ámbito de las relaciones laborales, encontramos que el control social informal lo ejercen los sindicatos, las coaliciones de trabajadores, las empresas, etc.

Por su parte el control social formal, es aquel en que participa el Estado en materia de trabajo; es ejercido -en el ámbito no penal- por la Autoridad Administrativa de Trabajo a través del Servicio de Inspección de Trabajo, el cual tiene amplia facultad para sancionar con medidas administrativas y pecuniarias, la infracción de las normas laborales.

En el ámbito penal, el control social formal lo ejercen las agencias ordinarias de control social penal, tales como son la policía, el Ministerio Público, Poder Judicial, INPE, etc., las cuales aplican las disposiciones del Código Penal, Código Procesal Penal y leyes especiales, dictadas para sancionar los delitos contra los derechos de los trabajadores.

\footnotetext{
1 VIllavicencio Terreros, Felipe. «Derecho Penal - Parte General». Editora Jurídica Grijley, Lima, 2000, p. 7.
} 


\section{DERECHO PENAL Y DERECHO PENAL DEL TRABAJO}

El Derecho penal es una clase de control social formal que, según la doctrina mayoritaria, admite dos puntos de vista para su definición, uno objetivo y otro subjetivo.

El Derecho penal objetivo (ius poenale) es el conjunto de normas jurídicas que establecen las conductas que deben ser consideradas como delictuosas, así como las sanciones (penas y medidas de seguridad) que deben imponerse a los sujetos que incurran en dichas conductas.

El Derecho penal subjetivo (ius puniendi) es el derecho que tiene el Estado de castigar determinadas conductas que considera atentatorias para las normas de convivencia social.

El Derecho penal puede dividirse en el Derecho penal general y Derecho penal especial.

Según HURTADO: "El derecho penal general fija los ámbitos de aplicación de la pena, define las condiciones necesarias para castigar y determina los tipos y límites de las sanciones penales. En cuanto el derecho penal especial, enuncia y describe los actos punibles, indicando cual es la pena aplicable al autor según la gravedad del acto contenido"

Teniendo en cuenta la variedad de criterios existentes en la doctrina para definir el Derecho penal general, establecer una definición que pueda sintetizar el contenido, características y ámbito de aplicación del Derecho penal del trabajo no es una tarea fácil, pues esta disciplina jurídica está aún en formación; es más, algunos sectores de la doctrina consideran que ni siquiera debería existir ya que para ellos la ley penal no es la mejor herramienta para lograr el respeto a los derechos de los trabajadores, proponiendo recurrir a otros medios de control social no penal con el fin de lograr este objetivo.

No obstante las dificultades antes descritas, nos atrevemos a definir el Derecho penal del trabajo como un sector del Derecho penal que sanciona aquellas conductas que lesionan bienes jurídicos de naturaleza laboral cuyos titulares son los trabajadores individuales $\mathrm{u}$ organizados colectivamente.

2 Hurtado Pozo, José. «Manual de Derecho Penal - Parte General I». 3ra. Edición. Lima: Editora Jurídica Grijley, Lima 2005, p. 11. 


\section{DERECHO PENAL DEL TRABAJO Y BIEN JURÍDICO}

La doctrina considera que el bien jurídico es un concepto operativo que nos permite delimitar qué es lo que debe ser objeto de protección penal en una sociedad.

Para HURTADO los bienes jurídicos, sean éstos individuales o colectivos, se pueden percibir "...como valores expresamente o implícitamente reconocidos por las reglas y principios constitucionales, que son necesarios para garantizar la relación de los fines del sistema social y el normal funcionamiento de éste" ${ }^{\prime \prime}$.

En las sociedades democráticas la lista de estos bienes jurídicos resulta ser muy extensa, así por ejemplo, tienen tal calidad la vida, la salud, la libertad, el patrimonio, el honor, el trabajo, etc., y son objeto de protección a través de diversos mecanismos como son el civil y el administrativo, por sólo mencionar los más importantes, pero también pueden serlo por medio de la ley penal; entonces, se convierten en bienes jurídicos penalmente tutelados.

Según BRAMONT "Los bienes jurídicos pueden clasificarse en bienes jurídicos referidos a las bases del sistema penal y bienes jurídicos referidos al funcionamiento del sistema penal"4.

El primer grupo de bienes jurídicos se refiere a aquellos relacionados directamente con el individuo en cuanto es una persona que se relaciona con otra a un nivel microsocial, aquí encontramos bienes jurídicos tales como la vida, la salud, la libertad, el patrimonio, etc.

El segundo grupo de bienes jurídicos está referido a las relaciones macrosociales de una persona con otras. Pueden ser colectivos, institucionales y de control.

Son colectivos, los relacionados a las necesidades de carácter social y económico, tales como la libre competencia, el medio ambiente, etc.; son institucionales, los relacionados con procedimientos $\mathrm{u}$ organismos destinados a garantizar los bienes jurídicos personales, aquí tenemos la Administración de Justicia, la fe pública, etc.; y finalmente los de control, están relacionados a la organización del Estado, entre éstos se encuentran la autoridad pública, la seguridad pública, la seguridad interior y exterior del Estado, etc.

\footnotetext{
Hurtado Pozo, José. Op. Cit., p. 27.

4 Bramont Arias, Luis A. y Luis Alberto Bramont-Arias TORRES. «Código Penal Anotado». Editorial San Marcos, Lima 1998, p.25.
} 
En materia de Derecho penal del trabajo no existe en la doctrina un criterio unánime sobre qué bienes jurídicos laborales deben ser objeto de tutela penal.

De una manera genérica, podemos decir en principio, que el bien jurídico penalmente protegido lo constituyen los derechos laborales cuya titularidad ostentan los trabajadores en tanto sujetos de relaciones jurídicas de trabajo, sean éstas individuales o colectivas.

De una manera concreta, el bien jurídico objeto de tutela penal será aquel que la ley penal, en cada caso concreto, seleccione como objeto de su protección, pues, no sería posible ni conveniente que todos los derechos derivados de la relación laboral gozaran de protección penal, sino solamente aquellos cuya lesión afecte gravemente a la sociedad.

Creemos que un indicador objetivo para identificar los bienes jurídicos laborales que deben ser objeto de protección penal, lo constituyen los Tratados sobre Derechos Humanos, los Convenios de la Organización Internacional del Trabajo (OIT) y los textos constitucionales, aunque en este último caso no debe olvidarse que no es requisito indispensable que los bienes jurídicos se encuentren consagrados en la Constitución para ser objeto de tutela penal.

En el caso peruano, somos de la opinión que el bien jurídico que se protege a través de los supuestos previstos por el artículo $168^{\circ}$ del Código Penal modificado por el Decreto Legislativo $\mathrm{N}^{\circ} 857$ y por la Ley No. 27983, Ley de Seguridad y Salud en el Trabajo, publicada en el Diario Oficial "El Peruano" el 20 de agosto de 2011, no es solamente la libertad de trabajo, sino una pluralidad de bienes jurídicos correspondientes a cada modalidad delictuosa, como son: el derecho a la libertad sindical, a la libertad de trabajo, la seguridad y salud en el trabajo, el derecho al trabajo, el derecho a la protección contra el despido arbitrario y el respeto a las decisiones de la autoridad pública competente en materia de trabajo.

\section{DERECHO PENAL DEL TRABAJO ÚLTIMA RATIO}

Modernamente, la intervención del Derecho penal como medio de control social sólo se justifica en la medida que persiga la protección de bienes jurídicos vitales para la vida en sociedad, y cuando los otros medios de control social hayan resultado insuficientes para dicha protección.

Admitir una posición contraria, abre la posibilidad a una aplicación desmedida de la represión penal a cualquier tipo de infracción sin importar su gravedad ni daño social. 
Creemos que el recurrir al Derecho Penal para sancionar conductas que lesionan bienes jurídicos laborales es una decisión de política criminal a la que se debe recurrir solo cuando los medios de control social estatales de carácter no penal hayan resultado insuficientes para proteger dichos bienes jurídicos, pues, tal como lo sostienen BAYLOS y TERRADILLOS "el fundamento de esta protección penal se encuentra en el propio carácter de las normas laborales como normas que (...) requieren de un sistema reforzado de sanciones para prevenir su ineficiencia" ${ }^{\prime \prime}$.

\section{FORMACIÓN HISTÓRICA DEL DERECHO PENAL DEL TRABAJO}

Las primeras concepciones sobre lo que debería entenderse por Derecho penal del trabajo están asociadas a la idea de represión de las luchas sociales de la clase trabajadora. Basta recordar que en Francia la Ley Chapelier de 1791 prohibió las asociaciones obreras y el Código Penal de 1810 que criminalizó la huelga; similar situación se presentó en Inglaterra donde las leyes de Combinación de 1799 y 1800 prohibieron las reuniones de los obreros para reclamar aumentos salariales, reducción de la jornada de trabajo o tratar de imponer condiciones al empleador.

En el Perú, si efectuamos una revisión histórica de nuestra legislación, encontraremos que la sanción penal de comportamientos vinculados a las relaciones laborales no es reciente, sino que por el contrario, es de antigua data. En las primeras décadas del siglo XX, se dictaron normas orientadas a reprimir los reclamos de los trabajadores, sobre todo el ejercicio de los derechos de sindicación y huelga. Así, por ejemplo, tenemos que el Decreto Supremo del 24 de enero de 1913, calificaba como delincuentes a quienes, individual o colectivamente, con hechos o amenazas, impedían el libre ejercicio de la industria, el comercio y el trabajo; mientras que el Decreto Supremo del 12 de mayo de 1920, con el objeto de limitar el ejercicio del derecho de huelga, estableció que quienes infringieran sus disposiciones serían juzgados como sediciosos o motinistas con arreglo al Código Penal.

No obstante lo antes señalado, desde los inicios del pasado siglo se dictaron algunas normas de protección penal de los trabajadores, como fue el caso de la Ley $N^{\circ} 1183$ del 23 de noviembre de 1909, que prohibía a las autoridades políticas intervenir en la contratación de servicios de peones u operarios de cualquier clase, para trabajos públicos y particulares. El artículo $2^{\circ}$ de

5 Baylos Grau, Antonio y Juan Terradillos. «Derecho Penal del Trabajo». Editorial Trotta, 2a Edición Revisada, 1977, p. 10. 
esta ley disponía que las citadas autoridades que por sí o por medio de sus tenientes enganchasen o reclutaran indios para cualquier trabajo público o de particulares sufrirían pena de cárcel por un año.

El Código Penal de 1924, no contempló en su articulado disposición alguna relativa a la represión penal de los delitos contra los derechos laborales; sin embargo, durante su vigencia se dictaron algunas disposiciones al respecto, pero formando parte de leyes de carácter laboral, como veremos a continuación.

Las normas de contenido penal empezaron a convertirse en un medio para proteger ciertos derechos laborales con la dación del Decreto Ley $\mathrm{N}^{\circ} 22126$ del 31 de marzo de 1978 sobre estabilidad laboral, el cual contenía normas relativas a la sanción penal del incumplimiento de las resoluciones de la Autoridad Administrativa de Trabajo relativas a la reposición del trabajador en el empleo, el abandono o cierre doloso del centro de labores y la utilización de documentos falsos en un procedimiento laboral. La Ley $\mathrm{N}^{\circ} 24514$ del 04 de junio de 1986, sobre estabilidad en el empleo, conservó disposiciones similares en materia penal.

Finalmente, al promulgarse mediante Decreto Legislativo $N^{\circ}$ 635, el Código Penal de 1991, se tipificó en su artículo $168^{\circ}$ algunos delitos contra los derechos de los trabajadores formando parte del Título IV "Delitos contra la libertad", Capítulo II Violación de la Libertad de Trabajo.

Posteriormente, la Tercera Disposición Derogatoria y Final del Decreto Legislativo $\mathrm{N}^{\circ} 857$ promulgado el 25 de setiembre de 1996 y publicado el 04 de octubre en el Diario Oficial "El Peruano", modificó el artículo $168^{\circ}$ del Código Penal, descriminalizando algunos supuestos contemplados en el texto original.

La Ley N²9783, Ley de Seguridad y Salud en el Trabajo, publicada en el Diario Oficial "El Peruano" el 20 de agosto de 2011, en su Cuarta Disposición Complementaria Modificatoria incorpora el artículo $168^{\circ}$-A al Código Penal, el cual considera como delito contra las condiciones de seguridad e higiene industriales la infracción de normas de seguridad en el trabajo que pongan en riesgo la vida, salud o integridad física del trabajador.

\section{DERECHO PENAL DEL TRABAJO Y POLÍTICA CRIMINAL}

La Política Criminal es la manera como el Estado reacciona frente al fenómeno de la criminalidad, con la finalidad de eliminarla, manteniendo de esta manera 
el orden establecido, respetando los derechos fundamentales y dentro del marco de lo que se entiende por Estado Democrático de Derecho.

Las tendencias de la Política Criminal en materia de Derecho penal laboral, podemos agruparlas de la manera siguiente:

Tendencia criminalizadora: Considera que la sanción penal permite reforzar la tutela de los derechos laborales, resultando más efectiva que las medidas de carácter administrativo y las propias del Derecho laboral.

Tendencia descriminalizadora: Persigue la no criminalización de las conductas antilaborales, sosteniendo que existen mecanismos extrapenales de protección de los derechos de los trabajadores que permiten sancionar dichos ilícitos sin tener que recurrir al Derecho penal.

Tendencia selectiva: Propugna la intervención del Derecho penal como instrumento necesario para garantizar un mínimo de tutela a ciertos derechos laborales que han superado el propio ámbito laboral para convertirse en derechos fundamentales reconocidos en los convenios internacionales y la Constitución.

\section{LOS DELITOS LABORALES EN EL CÓDIGO PENAL DE $1991 \mathrm{Y}$ LEYES ESPECIALES}

El legislador peruano, siguiendo la tendencia de la mayoría de los Códigos Penales latinoamericanos, ha ubicado en nuestro Código Penal de 1991 los delitos contra los derechos laborales en el Título IV Delitos Contra la Libertad, Capítulo VII Violación de la Libertad de Trabajo, artículo $168^{\circ}$.

El texto original del artículo $168^{\circ}$ del Código Penal tipificaba el delito de violación de la libertad de trabajo de la manera siguiente:

"Artículo 168.- Será reprimido con pena privativa de la libertad no mayor de dos años el que obliga a otro, mediante violencia o amenaza, a realizar cualquiera de las conductas siguientes:

1. Integrar o no un sindicato.

2. Prestar trabajo personal sin la correspondiente retribución.

3. Trabajar sin las condiciones de seguridad e higiene industriales.

4. Celebrar contrato de trabajo o adquirir materias primas o productos industriales o agrícolas. 
La misma pena se aplicará al que retiene remuneraciones o indemnizaciones de los trabajadores o no entrega al destinatario las efectuadas por mandato legal o judicial; al que incumple las relaciones consentidas o ejecutoriadas dictadas por la autoridad competente; y al que disminuye o distorsiona la producción, simula causales para el cierre del centro de trabajo o abandona éste para extinguir las relaciones laborales".

La modificación introducida por la Tercera Disposición Derogatoria y Final del Decreto Legislativo $N^{\circ} 857$ al artículo $168^{\circ}$ del Código Penal, descriminalizó varios supuestos contemplados en el texto original del artículo $168^{\circ}$ quedando el nuevo texto redactado en los términos siguientes:

"Artículo 168.- Será reprimido con pena privativa de la libertad no mayor de dos años el que obliga a otro, mediante violencia o amenaza, a realizar cualquiera de los actos siguientes:

1. Integrar o no un sindicato.

2. Prestar trabajo personal sin la correspondiente retribución.

3. Trabajar sin las condiciones de seguridad e higiene industriales determinadas por la autoridad.

La misma pena se aplicará al que incumpla las resoluciones consentidas o ejecutoriadas dictadas por la autoridad competente; y al que disminuye o distorsiona la producción, simula causales para el cierre del centro de trabajo o abandona éste para extinguir las relaciones laborales".

Posteriormente la Ley № 29783, Ley de Seguridad y Salud en el Trabajo, ha tipificado los delitos contra las condiciones de seguridad e higiene industriales en los términos siguientes:

"Artículo 168-A. Atentado contra las condiciones de seguridad e higiene industriales

El que, infringiendo las normas de seguridad y salud en el trabajo y estando legalmente obligado, no adopte las medidas preventivas necesarias para que los trabajadores desempeñen su actividad, poniendo en riesgo su vida, salud o integridad física, será reprimido con pena privativa de libertad no menor de dos años ni mayor de cinco años.

Si, como consecuencia de una inobservancia de las normas de seguridad y salud en el trabajo, ocurre un accidente de trabajo con consecuencias de muerte o lesiones graves, para los trabajadores o terceros, la pena privativa de libertad será no menor de cinco años ni mayor de diez años." 


\section{CONCLUSIONES}

1. El Derecho penal del trabajo es un medio de control social que constituye un instrumento eficaz de protección de los derechos laborales, al que debe recurrirse sólo frente al fracaso de los mecanismos de control social extrapenal.

2. La criminalización primaria de ciertas conductas como delitos laborales debe hacerse teniendo en cuenta la lesión que ocasionen a bienes jurídicos trascendentes, entendiéndose por éstos, aquellos cuyo origen lo encontramos en los Tratados internacionales sobre derechos humanos, los Convenios de la Organización Internacional del Trabajo (OIT), la Declaración sobre Principios y Derechos Fundamentales en el Trabajo, y en el texto constitucional.

3. La regulación contenida en nuestro Código Penal para proteger los derechos de los trabajadores es imperfecta, pues los supuestos típicos que contempla se circunscriben mayoritariamente a la coacción, y la pena con la que se sanciona tales delitos es mínima. Se ignora que la coacción no es la forma más común de atentar contra los derechos de los trabajadores y que la escasa penalidad con que se reprime los delitos laborales no cumple un fin disuasivo.

4. La ubicación sistemática de los delitos laborales dentro del Título relativo a los delitos contra la libertad, parecería encontrar explicación en el hecho que los tres primeros incisos del artículo $168^{\circ}$ protegen bienes jurídicos laborales de agresiones realizadas a través de la coacción (violencia o amenaza) que resulta ser la forma más difundida de violación del derecho a la libertad en general, por lo que siguiendo este criterio, los delitos contra los derechos laborales, según nuestro Código Penal, serían en realidad una modalidad de delitos contra la libertad; sin embargo, esta interpretación no resulta exacta, pues, en la segunda parte del artículo objeto de comentario encontramos que se sancionan comportamientos de distinta naturaleza en los que no se exige la coacción para que se configure el delito, ya que los bienes jurídicos resultan ser otros diferentes de la libertad.

5. La Ley N²9783 incorpora el artículo 168 - A al Código Penal, lo cual constituye un avance respecto de la anterior redacción del artículo $168^{\circ}$ del Código Penal, pues tipifica con claridad el delito de atentado contra las condiciones de seguridad e higiene industriales. 
REFERENCIAS BIBLIOGRÁFICAS:

Baylos Grau, Antonio y Juan TerRadillos. «Derecho Penal del Trabajo». $2^{\text {a }}$. Editorial Trotta, Edición Revisada, 1977.

Bramont ARIAS, Luis A. y Luis Alberto Bramont ARIAS TORReS: «Código Penal Anotado». Editorial San Marcos, Lima, 1998.

Hurtado Pozo, José. «Manual de Derecho Penal - Parte General I». Editora Jurídica Grijley, 3ra. Edición, Lima, 2005.

Villavicencio Terreros, Felipe. «Derecho Penal - Parte General». Editora Jurídica Grijley, Lima, 2000. 